\title{
Integrating aerial videography and digital photography with terrain modelling: an application for coastal geomorphology
}

\author{
David Livingstone ${ }^{\mathrm{a}, *, 1}$, Jonathan Raper ${ }^{\mathrm{b}, 2}$, Timothy McCarthy ${ }^{\mathrm{b}, 3}$ \\ a Department of Geography, Portsmouth University, Buckingham Building, Lion Terrace, Portsmouth, Hants PO1 3 HE, UK \\ ${ }^{\mathrm{b}}$ Department of Geography, Birkbeck College, 7-15 Gresse St., London W1P 2LL, UK
}

Received 15 January 1998; received in revised form 25 August 1998; accepted 29 December 1998

\begin{abstract}
The integration of airborne imagery, derived from video and digital camera imagery, with terrain data from ground survey is within the scope of low-budget, small scale geomorphological investigations. Geographical Information Systems (GIS), available on standard desktop computer systems, are suitable for the integration of this imagery with other geomorphological survey data. Different georeferenced datasets can be combined to produce visualisations that can aid interpretation and measurement that may otherwise be difficult to achieve. As with all remote-sensed data, the synoptic view has considerable benefits, especially when combined with ground fieldwork. There are a variety of methods that can be used to collect and process these data dependent upon the aims of the geomorphologist. There is always a trade-off involving the cost, spatial resolution and temporal control for each of these methods, and this trade-off ultimately determines the absolute accuracy and suitability of the imagery for the purposes required. Although it always seems desirable to attempt to collect the highest resolution imagery possible, using the greatest degree of control and results that can enhance the value of standard field techniques. Decisions involving choice of capture equipment, methods of processing, methods of establishing position and attitude, and ground control techniques determine the quality of the imagery produced. The rectified imagery, when combined with digital terrain models, significantly aids the interpretative process and enables features with boundaries visible on the ground to be delimited on the terrain model and related to contour plots. Airborne video is a cheap, easily available and flexible method of producing this imagery. Recent advances in digital techniques have resulted in digital video and digital camera photography becoming alternatives to conventional video. The advantage of using a digital format is that the number of processing steps is reduced with potential savings in equipment, cost and time as well as improvements in resolution and accuracy. Digital camera photography shows particular promise with spectacular improvements in image resolution and continually falling costs making it an increasingly viable alternative to standard photographic film, particularly when the data are to be transferred onto a computer system. The accuracy and resolution that can be obtained are superior to those obtainable from orbiting systems and future availability of sensors covering a variety of bandwidths will enable multi-spectral analysis. The combination of this kind of imagery with terrain data is a powerful one, either for data
\end{abstract}

\footnotetext{
* Corresponding author. E-mail: david.livingstone@port.ac.uk.

${ }^{1}$ Formerly of School of Geography, Kingston University, Penrhyn Rd., Kingston Upon Thames, KT1 2EE, UK.

${ }^{2}$ Present address: Department of Information Science, City University, Northampton Square, London EC1V 0HB, UK. E-mail: raper@soi.city.ac.uk

${ }^{3}$ Present address: Airborne Videography Ltd., 22 Heathfield Gardens, Chiswick, London W4 4JY, UK. E-mail: tim@avxs.demon.co.uk
} 
visualisation and interpretation or for feature definition and measurement of change. (C) 1999 Elsevier Science B.V. All rights reserved.

Keywords: airborne videography; digital photography; terrain analysis; digital terrain model; geographical information systems (GIS); coastal geomorphology

\section{Introduction}

Many forms of geomorphological investigation require accurate, high resolution and frequently updated data on significant forms, sedimentary materials and vegetation in the environment of study. When used in conjunction with fieldwork, remotely sensed imagery from satellite or airborne sensors can be an important source of such data. Geomorphological site studies are enhanced by high resolution visible or multispectral image data $(\sim 1 \mathrm{~m}$ ground resolution) collected at short intervals ( $\sim$ weekly / monthly) or at times dictated by the magnitude and frequency of geomorphological events (especially low frequency/high magnitude events). For much of the last 3 decades, these requirements have not been fully met by any one form of widely available remotely sensed imagery. Satellite sensors currently offer image data at resolutions $>5-10 \mathrm{~m}$, may be obscured by cloud and in the main cannot be directed to capture imagery at specified times. Aerial photography does capture high resolution photographs and can be directed to locations of interest at appropriate times, but due to the special requirements of large-format aerial camera mounting and operation, aerial photography campaigns are expensive to commission and often take some time to implement. Cost, the desire for spatial resolution and a need for temporal control over the imagery are often in competition. Aerial photography in archives often provides useful imagery but may not be timely, have the right coverage, be radiometrically ideal, or be at the necessary resolution.

In the last 3 years, new forms of visible and multispectral sensor have been developed which can be deployed cheaply and easily on standard light aircraft and which produce machine-readable imagery from video or digital cameras (King, 1995). Where sites are inaccessible or fragile, the availability of videography and digital photography makes it possible to build up image-bases to support qualitative and quantitative studies. Imagery produced by 'aerial videography' is stored in an analogue video form, at high frame rates (between 25-30 frames per second). This is a high enough sampling rate to observe geomorphological processes, e.g., wave run up a beach, flood events or mass movements. Video imagery is usually captured in the visible part of the spectrum (although some multispectral sensors are used) and typically has ground resolution of the order of $0.75 \mathrm{~m}$ at flying heights of $500-700 \mathrm{~m}$. Using multimedia tools on standard computer systems, machine-readable video data can be converted into digital imagery or movies for further processing. A relatively recent alternative is imagery produced by 'digital photography', typically stored at frame rates of 3-4 s per frame. This is in three bands, usually red, green and blue, and can now give $<20$ $\mathrm{cm}$ ground resolution at flying heights of 500-700 $\mathrm{m}$. The output is inherently digital and needs no further processing to be used in standard computer systems.

The availability of such imagery has now opened up new sources of machine-readable data to geomorphologists. These data can be used to support site studies through image-mapping and integration with terrain data in geographical information systems (GIS). Radiometrically-appropriate, high resolution imagery when integrated with ground surveyed or photogrammetrically-derived terrain data enhances both the interpretation and measurement of morphometric information. There is the potential to provide a comprehensive source of information, which can be explored for process signatures in morphodynamic studies. The case study described in this paper, uses standard GIS tools and simple data capture methods to produce relatively high quality terrain representations, suitable for modelling, analysis and visualisation. However, despite the recent availability of this imagery and associated GIS-based terrain modelling tools, there are few accounts of how this integration can be achieved and what accuracy can be expected under a range of capture, processing and integration circumstances. 
Accordingly, this paper aims to set out the basic principles of image collection and processing and to show how videography and digital photography data can be integrated with terrain data in a GIS for morphodynamic investigations. The technology is discussed in order to enable geomorphologists to decide on a suitable mode of data collection and to indicate the likely bounds on the errors, which can be expected during processing, and integration. With reference to coastal morphodynamic research being conducted by the authors on the North Norfolk coast of Eastern England, case studies of the use of videography and digital photography will be presented. The purpose of the studies is to assess the relative potential of these data and the relevance of the techniques to geomorphology.

\subsection{Geomorphological requirements of imagery and terrain data}

The dynamic nature of the coastal environment requires either the capture or availability of spatially and temporally accurate data. In recognition of the need for accurate, and nationally available coastal zone mapping, the Hydrographic Office and Ordnance Survey (Westley and Rhind, 1993) produced a prototype for mapping the coastal zone of the UK. Until now, no formal product with national coverage has been released. For research and detailed management and monitoring purposes, the complex nature of coastal interactions, operating at a variety of different spatial and temporal scales, means that standard mapping is unlikely to be the only data source required. Aerial photography, satellite imagery, ground and bathymetric survey, and historical maps and photographs are all suitable data sources which can be combined to produce coastal mapping for measuring geomorphological change.

When imagery and terrain data are acquired from third party sources, the resolution/radiometry of such data must be taken as given. In these circumstances, the geomorphological study must adapt to the information content of the data. This may involve having to deal with incomplete spatial coverage or images captured at an inappropriate time, requiring inferences to be made. It also requires reliable reports on the quality of the data from the data supplier, to enable its suitability to be determined. In cases where imagery is collected within and for the geomorphological study, the researcher wishes to specify the spatial and temporal accuracy which is needed in order to identify geomorphologically significant features and to measure critical change. The Oxford English Dictionary defines accuracy as 'conformity to a standard or to truth' and the assessment of accuracy is clearly an important component of analysis. However, accuracy is both an absolute and relative term.

In absolute terms ('conformity to a standard'), position in $x, y$ and $z$ dimensions, can be assessed by reference to any suitable local, national or global datum. The aerial platform used for capturing imagery has an absolute attitude with reference to a datum, and the image collection device has a fixed or variable attitude with reference to the platform. The sensor technology used has an absolute range of radiometric sensitivity and a resolving power dependent on the number of samples taken in the scene. Terrain data can be derived photogrammetrically from imagery by stereocorrelating two adjacent overlapping images, or, alternatively, by ground survey using a total station. The accuracy of imagery and terrain data should be determined with reference to these measurable standards. Although in some remote areas it may be necessary to create a local coordinate datum and later determine the positional difference between the local and global datum. Accuracy will also be degraded by the post-processing of the imagery to remove distortion by warping, by georeferencing it to a coordinate datum and by stereocorrelation.

Accuracy, or 'conformity to truth', must be defined by the research objectives, specifically by reference to the ontology of the phenomena being investigated (Raper, 1998). In other words, the imagery must have positional, radiometric, resolving and geometric accuracy relative to a datum sufficient to allow the correct identification of the dimensions of the smallest geomorphological features of importance and to permit the conjectural definition of new features (Raper and Livingstone, 1995). For the measurement of both change and dimension, it is accuracy relative to a datum that is important. The accuracy of the feature location to a global framework, such as OSGB 1936 datum or WGS84, can be of less importance in local geomorphological studies. The 
resolving power of an image can be enhanced by the relative juxtaposition of datasets such as imagery and terrain models with different resolutions and confidence levels. Fieldwork and 'ground-truthing' are necessary to be able to define and control 'required accuracy' and to prevent the identification of significant features being driven de facto, by the need to increase the accuracy relative to a global framework. Clearly, 'required accuracy' will be different for each geomorphological study and no universal standard of accuracy can be defined as particularly applicable to geomorphology as a whole. The key issue is whether the 'required accuracy' falls within the bounds of the accuracy available in the source imagery in combination with terrain data. Whether this is the case depends upon choices made in the collection, processing and integration of the data.

\subsection{Mapping morphodynamic change of coastal spits on the North Norfolk coast of Eastern England}

The North Norfolk coast of Eastern England, from Hunstanton to Blakeney, is composed of sand dunes and barrier beaches backed by salt marsh punctuated every $5-8 \mathrm{~km}$ by mesotidal/macrotidal channels (Pearson et al., 1990). Many of the tidal channels are bounded by extensive ebb tidal deltas, swash bars and spits. Spits are elongated supratidal bars of unconsolidated sediment attached to the adjacent barrier at one end. They are usually recurved landwards at their terminus and they develop wherever the coastline is wave-dominated, has adequate sediment supply and a space into which to prograde. The dynamic form of spits reflects a balance between wave and tide energy in the short term and relative sea level change in the medium and long term (Hayes, 1979). Carter (1988) suggested that coastal cells powered by oblique incident wave arrival may provide the mechanism by which adjacent barriers supply sediment to the spits and ebb-tidal deltas. Since the tidal channels are barriers to longshore sediment movement these associated sedimentary forms also buffer coastal sediments and act as reservoirs. Hence, spits and bars, marginal to tidal channels, may be both sensitive indicators of aggregate coastal change and reservoirs of sediment. The sediment budgets of these features, may be of considerable importance to the management of the adjacent coastline on an annual and decadal scale. The potential importance of these features compared to the generally poor knowledge of their behaviour in the UK, was identified by the Flood and Coastal Defence Division of the Ministry of Agriculture, Fisheries and Food (MAFF). This resulted in a 1992 review of research on coastal morphodynamics (MAFF, 1992) and subsequent research programme (MAFF, 1995).

The case study provides a baseline record of the behaviour of a specific spit and tidal channel. Monitoring of morphology, sedimentary composition and wave/tidal processes was begun in the Brancaster Channel and adjacent Far Point spits of Scolt Head Island in 1992 (Bristow et al., 1993). Scolt Head Island is a $7 \mathrm{~km}$ long barrier island which has been constructed during the Holocene from a series of westerly-recurved spits, each of which now encloses a saltmarsh (for location map, see Fig. 1). Terrain elevation and surface sedimentary composition data for the currently active Far Point spits and adjacent ebb tidal delta have been captured at 6-monthly intervals since April 1992. Subsequently (19951997), this frequency was increased to monthly intervals. The main technique has been a ground survey with a surveying total station from the same fixed monumentation defining a local coordinate system. In August 1993, aerial videography was collected (almost) synchronously with the ground survey as an initial experiment, and then again every 6 months 1995-7 until November 1997, when high resolution digital photography was introduced as a further experiment. Wave data have been collected offshore of Scolt Head Island using a wave buoy over a 15-month monitoring season to provide information on process input to the spit environment.

This record of terrain elevation, surface sedimentary composition and aerial imagery provides a high resolution record of geomorphological change for the spits at Far Point. This record builds on historical mapping which was started in 1822 by Thomas Telford for nearby sea-wall construction. The record was continued by the Ordnance Survey of Great Britain through their topographic mapping and by the Hydrographic Office of the Admiralty through their marine charting during the 19th and 20th centuries. Large scale maps of the outlines of the spits were made between 1925 and 1958 by Steers (Steers, 1960). The Cambridge University Aerial Photogra- 


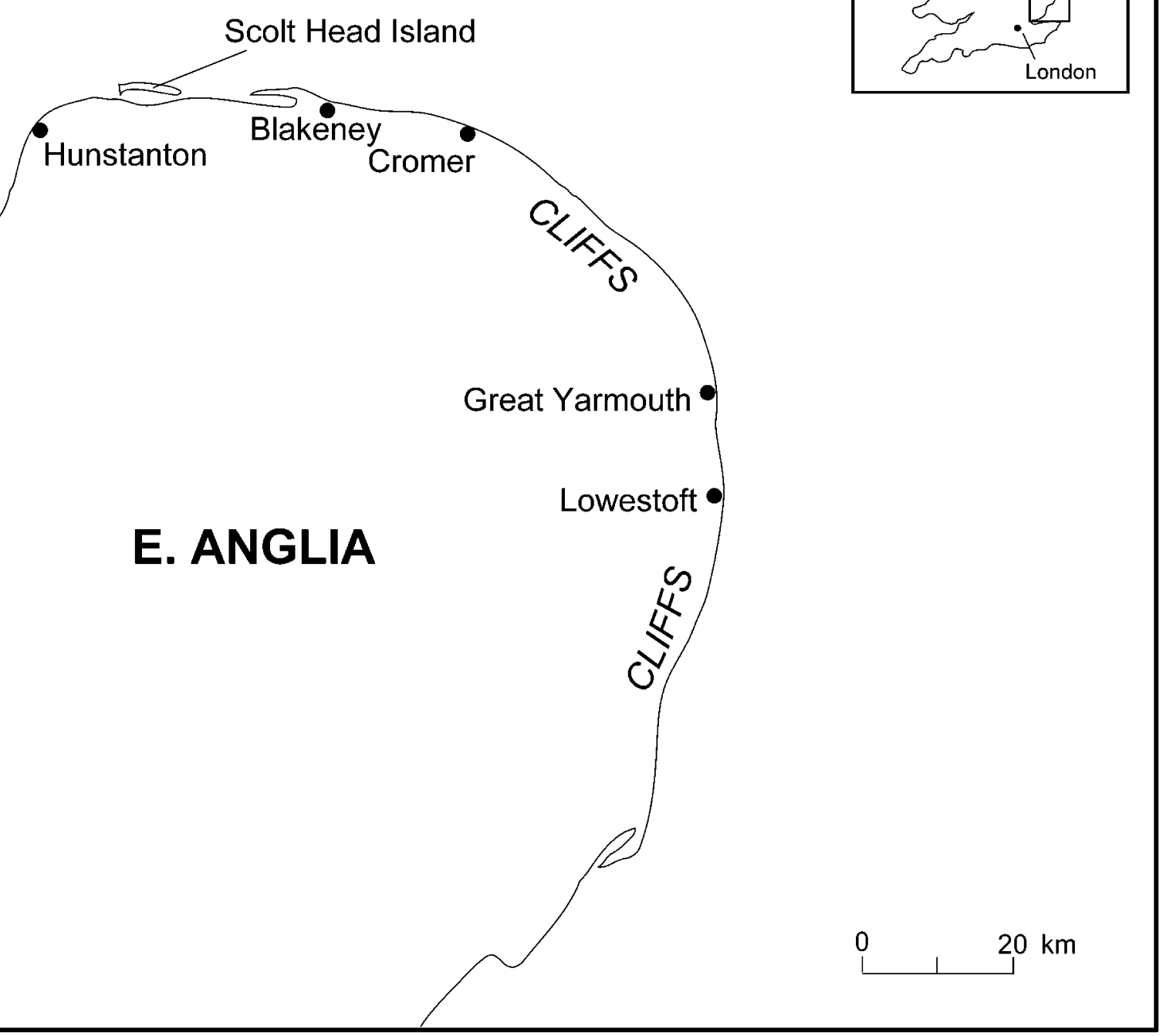

Fig. 1. Location map of Scolt Head Island, North Norfolk, United Kingdom.

phy Unit photographed Scolt Head Island in 1965, 1967, 1974, 1979, 1984 and 1990 from which Davis (1991) compiled a further set of spit outlines (mosaiced in Fig. 2). Davis (1991) showed that the spits at
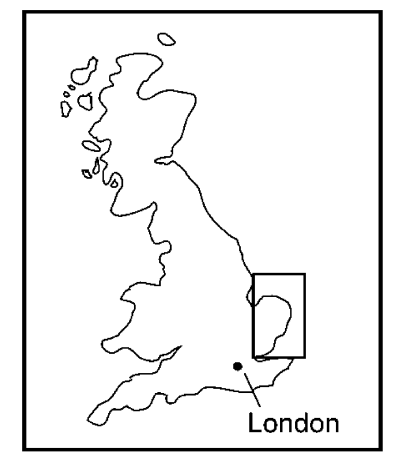


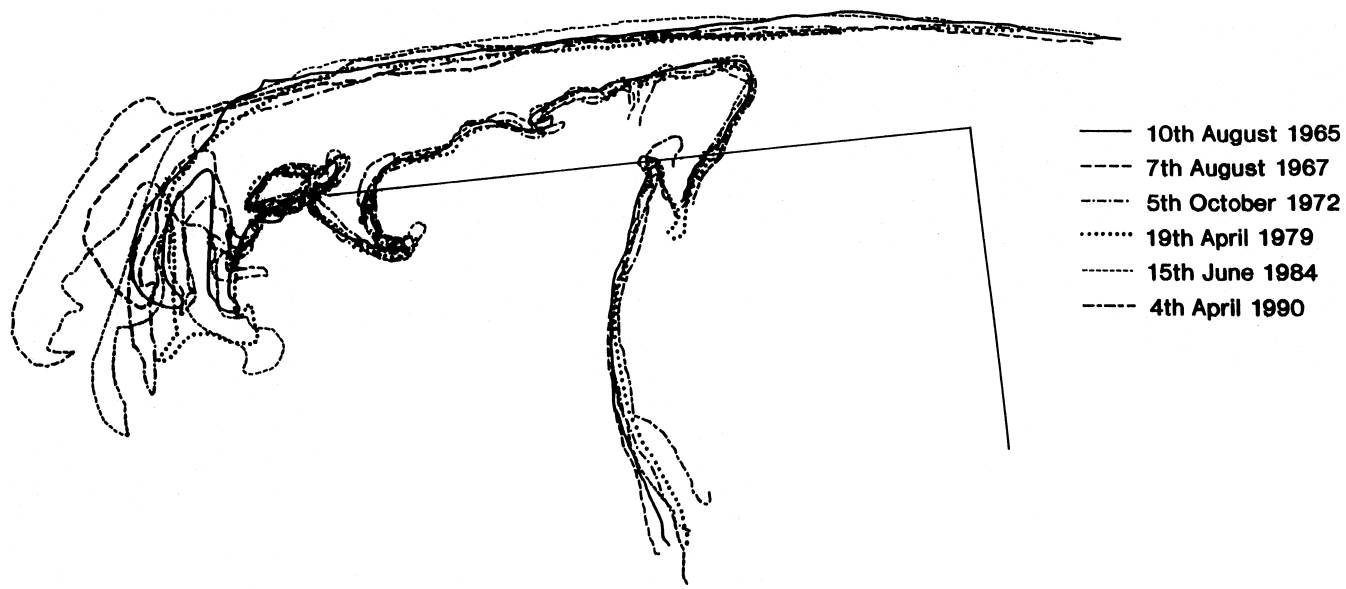

Fig. 2. Outlines of Far Point spits, Scolt Head Island 1965-1990 (Davis, 1991).

The most recent surveys of elevation since 1992, show that the spit develops through a process of longshore transport. Sediment eroded from the shoreface, close to the end of the barrier beach, becomes deposited at the very end of the spit (as in the 1990 outline in Fig. 2). Washover appears not to be important on the spits at Far Point except in high magnitude storm events. After a period of several years, a new spit is formed (as in 1994), which initially extends from the beach of the main barrier. The new spit then follows a similar path to the old spit further to the west, becoming elongated and progressively recurved. The extension of a new spit appears to coincide with the gradual degradation of the older spit. This is interpreted to indicate that the new spit is capturing sediment which might otherwise have been supplied to the older spit. The processes which lead to the degradation of the older spit are attributed largely to tidal currents in Brancaster Channel, which trim the end of the spit and create breakthroughs. This is the most common cycle of spit development and degradation; at other times, spits have been observed to coalesce or to be completely removed. The end result is a gradual accretion process, where the net deposition (perhaps contributing to the construction of a spit 'platform' as Meistrell, 1972 suggested) is much less than the sum of each of the recurved spits.

The morphological and sedimentological studies undertaken since 1992 have established the overall nature and style of spit development (Bristow et al.,
1993, in preparation). Quantitative aspects of spit evolution, such as sediment budgets for specific periods defined by wave climate/tidal cycles, can be derived from the conventional terrain models but are enhanced by integration of imagery. For more sophisticated analyses, such as attempting to determine the role of coastal cells in sediment movement (May and Tanner, 1973), or monitoring spit profile change, the integration of imagery and terrain modelling in a GIS would appear to be almost a prerequisite for studies on any significant scale. Objectives such as these define the accuracy needed for this geomorphological study. The Far Point spits are up to $500 \mathrm{~m}$ long, $100 \mathrm{~m}$ wide and have a vertical relief similar to the tidal range, i.e., $4 \mathrm{~m}$. Over the 4 -year period 1993 to 1997 the spits have been displaced by up to $100 \mathrm{~m}$, in one case experiencing erosion at a shoreface cross-section of over $10 \mathrm{~m}$ horizontally in a single storm. These observations suggest that $5-10$ $\mathrm{m}$ horizontal accuracy and $10-20 \mathrm{~cm}$ vertical accuracy should be sufficient to study the morphodynamic response of these spits to wave and tidal forcing.

\section{Obtaining high resolution remotely sensed im- agery}

Capturing high resolution remotely-sensed imagery involves the choice of a sensor and a platform with the associated mechanisms to track position, 
attitude and height. No single set of options can be considered optimal since the diverse measurements on the platform must be integrated in real time with minimal latency. Accordingly, this section sets out the key advantages and disadvantages of each option and suggests some effective combinations.

\subsection{Capture method}

In a general order of importance, the key attributes of remotely sensed image capture are radiometry, resolution, and geometry. In the case of radiometry, there is a range of options from hyperspectral, through multispectral and single band imagery (usually optical or infra-red). In general, single band optical sensors are the cheapest and most widely available through the professional popularity of video, although a wide range of sensors have been deployed in aerial surveys (King, 1995). The sensors in the Kodak Digital Science range of cameras (Eastmann Kodak, 1997) have a peak sensitivity in the range $550-800 \mathrm{~nm}$. This range covers the visible and near-infrared part of the spectrum, filters are required to select three wavebands (one for each available sensor) which can be captured in up to 12 bits per waveband. This study has focussed on video and digital camera optical imagery as the research aim was to carry out image-mapping from the air.

Applying a sensitivity analysis to radiometry implies examining the transformations between the image of the scene resolved by the optics of the lens and the final stored digital image. Table 1 shows a comparison between traditional aerial photography and satellite-based multispectral scanner and the two more recent formats of video and digital photography. The transformations between scene and image for video are dominated by the need to be able to display the image on a television. The solution is to modulate the image captured on the CCD array onto an analogue waveform in either PAL or NTSC format. If video imagery is to be used in image-mapping the waveform has to be de-interlaced (the images are composed of even and odd-line 'frames') and re-digitised from analogue to digital form. This transformation degrades the original digital image; however, video is still the only format with high enough frame rates to give total frame coverage along-track. By contrast, digital cameras simply store the original CCD array, however, at present, this cannot be done faster than once every 3-4 s and this delay makes for some uncertainty in positioning (Koh and Edwards, 1996).

The resolution of remotely sensed image capture depends on height, lens, and the sensor. Flying height is often the key control over resolution since the resolution offered by a sensor is fixed with respect to a scene. Clearly, the lower the aerial survey the narrower the swath width captured on any sensor, although the swath can be increased by switching to a wider lens if the additional radial distortion in the image can be accommodated. Many professional video formats offer a range of lenses from super wide fisheye to telephoto. In video, the resolution is asymmetrically determined. The vertical resolution is

Table 1

Transformations between scene and image for different capture technologies with advantages and disadvantages

\begin{tabular}{|c|c|c|c|}
\hline Capture method & Transformations & Advantages & Disadvantages \\
\hline Photography & $\begin{array}{l}\text { photo paper imaging }>>\text { scanner } \\
\mathrm{CCD}>>\text { array }>>\text { image }\end{array}$ & $\begin{array}{l}\text { resolution } \\
\text { standard }\end{array}$ & $\begin{array}{l}\text { needs digitising } \\
\text { cost to commission }\end{array}$ \\
\hline Multispectral scanner & $\begin{array}{l}\text { CCD scanlines }>>\text { array }>> \\
\text { telemetry }>>\text { multiband image }\end{array}$ & $\begin{array}{l}\text { radiometry } \\
\text { platform } \\
\text { standard }\end{array}$ & $\begin{array}{l}\text { expense of imagery } \\
\text { deployment inflexible }\end{array}$ \\
\hline Video & $\begin{array}{l}\text { CCD scanlines }>>\text { array }>> \\
\text { waveform }>>\text { digitiser }>>\text { image }\end{array}$ & $\begin{array}{l}\text { cheap } \\
25 / 30 \text { fps } \\
\text { standard }\end{array}$ & $\begin{array}{l}\text { geometry variable } \\
\text { radiometry interlaced }\end{array}$ \\
\hline Digital camera & $\begin{array}{l}\text { CCD imaging }>>\text { array }>>\text { image } \\
\text { (soon }>>\text { MPEG video) }\end{array}$ & $\begin{array}{l}\text { resolution } \\
\text { format } \\
\text { radiometry }\end{array}$ & $\begin{array}{l}\text { speed of frames } \\
\text { expense of cameras }\end{array}$ \\
\hline
\end{tabular}


controlled by the number of lines in the video format (450 lines in S-VHS) and the horizontal resolution is controlled by the quantisation of the 'image modulated onto a waveform' along each line. Generally, the number of lines is fixed and the quantisation along each line is determined by a standard aspect ratio (differs for PAL and NTSC).

The geometry of remotely sensed image capture depends on the stability of the platform, the information captured about height, attitude and position, and the optics of the lens. With detailed knowledge of lens optics, it is possible to correct inherent distortions; however, remotely sensed image capture using video introduces a number of uncertainties into the geometry of the image. Specifically, professional video cameras have optical filters to split the light captured from the image scene into red, green, and blue segments, each of which is delivered to a separate CCD array. These red, green, and blue signals are recombined into luminance and chrominance signals ready for modulation onto the appropriate waveform. The rapid turnover of video cameras also mean that detailed photogrammetric testing is rarely carried out on specific combinations of lens and CCD chips (Um, 1997).

\subsection{Platform monitoring}

The key issues in monitoring the platform are, position in a horizontal coordinate system, height above a datum and attitude of the aircraft and the sensor. If the selection of positional and attitude monitoring methods are independent of each other then any latency (time delay) between the methods can degrade the record considerably. While platform position and attitude is closely controlled for satellites in space, aircraft collecting imagery can experience extreme short-term variations in position, height and attitude. These variations can either be eliminated/severely reduced by stabilisation of the aircraft (as in the case of some gyro-stabilised survey aircraft), logged and corrected for in post-processing, or ignored at capture-time. The latter option is only possible for image-mapping if there is comprehensive heightened ground control allowing rectification of the image and recovery of attitude.

Table 2 outlines the main methods of platform monitoring and gives estimates of their absolute accuracy. The key position fixing tool in aerial survey is the Global Positioning System (GPS), although the standard $1 \mathrm{~Hz}$ update rate can lead to latency problems when synchronising position with height and attitude. Attitude can be recovered using differential GPS antennae on aircraft wing tips, however, there are still latency problems and there must be a differential GPS correction service available at fly-time. Height is often established from aircraft barometric instruments. However, some recent experiments with laser-scanners offer new potential if they can be integrated with GPS at sub-1 Hz latency (Lohe, 1997). Optimum positioning accuracies based on real-time platform monitoring are rarely better than $5 \mathrm{~m}$ horizontally with differential GPS or $20 \mathrm{~cm}$ vertically with a laser scanner.

Table 2

Methods of aerial platform monitoring and estimates/assessment of accuracy/quality

\begin{tabular}{lll}
\hline Platform & Options for acquisition & Accuracy/Quality \\
\hline Position & Image bounds by orbital track/sensor FOV & $\sim 100 \mathrm{~m}$ \\
& Image centre by GPS /DGPS & $\sim 100 \mathrm{~m} / \sim 5 \mathrm{~m}(\sim 1 \mathrm{~Hz})$ \\
& Image bounds by DGPS + image geometry & $\sim 5 \mathrm{~m}$ \\
Attitude & Ground control & $\sim 1 \mathrm{~m}$ \\
& Orbital track/FOV & stable \\
DGPS & unstable; 1-20 Hz latency \\
Height & Flux & stable; $20 \mathrm{~Hz}$ latency \\
& Orbit & excellent to WGS84 at image centre \\
& Aircraft barometer & nominal ASL for platform \\
& Laser ranging & excellent to point $(\sim 1 \mathrm{~Hz})$ \\
& Laser altimetry & very good to 200 Hz points
\end{tabular}




\section{Georeferencing imagery}

Once captured, video or digital photography must be rectified to remove lens distortion and tilt (in order to reinstate a planar, orthogonal image) and georeferenced to be integrated with terrain data and digital mapping. Rectification to remove distortion can be achieved using camera models for lens distortion and attitude sensing to remove tilt, or distortion can be removed by post-processing using rectification during image georeferencing. Georeferencing can be achieved either by platform monitoring as described above, or by the use of ground control points visible in the imagery. If georeferencing is based on platform monitoring then image centre and corner points must be available for the imagery corresponding to the exact time of capture. If georeferencing is based on ground control where possible such control should be bright and in contrast to the surrounding surface. The control needs to be fixed in position over time, and be positioned with a high level of accuracy. The density of visible ground control points within a frame is of importance with at least three points for simple rectification and many more if terrain data are to be extracted. If the imagery is to be used for digital photogrammetry then the software will have minimum requirements for frame overlap and common control points, figures of $30 \%$ overlap and five or six control points would be typical.

Given the required accuracy specified for this geomorphological study, it was decided that rectification and georeferencing could be achieved to a sufficient accuracy by the use of ground control points. As a consequence, no in-aircraft attitude monitoring was carried out. Video and digital cameras were fixed with respect to the aircraft, which maintained a level straight course with image capture suspended when executing turns. The position of the aircraft was tracked for auditing purposes using differential GPS. The video was synchronised with GPS positions at $1 \mathrm{~Hz}$ using a synchronisation box (Fig. 3) which stores position in an unused part of the vertical line blanking interval of the video (Cooper et al., 1995). In a November 1997 experiment, video and digital camera imagery was captured simultaneously, allowing the direct comparison of the imagery derived from each method. Ground control was

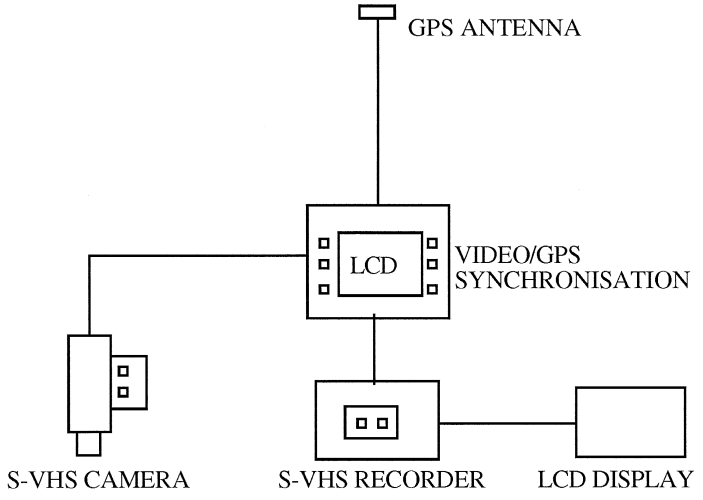

Fig. 3. Video image synchronisation with GPS signals.

placed at intervals of $100-200 \mathrm{~m}$ on the spits and surrounding area so as to maintain a comprehensive coverage in the imagery: in most cases $6-8$ points were visible in the images. The centre of ground control points (white markers) was surveyed using a regularly serviced total station based on fixed monumentation to absolute accuracies of $2-3 \mathrm{~cm}$ during or after each aerial survey. Rotations to the Ordnance Survey national datum and GPS-based WGS 84 are available.

Video imagery was captured in the earliest survey in 1993 using a Sony S-VHS camcorder but subsequently using a S-VHS Pulnix camera with separate optical head. The recorded S-VHS imagery was digitised using a framegrabber at 576 by 768 pixels in 24 bit colour. By contrast, the digital photography was captured using a Kodak DCS 460 camera back mounted on a Nikon SLR camera, generating images at 3060 by 2036 pixels in 24 bit colour (32 bit colour is also available). Fig. 4 shows two images of the Far Point spits from the video and digital captured simultaneously in November 1997 which are presented here in grayscale. The digital camera image shown in Fig. 4 is only one quarter of an image and clearly has better resolution and radiometry as it does not have alternate image fields interlaced to make a frame as in video imagery. Note that such digital cameras were effectively unavailable at the start of this monitoring process in 1993 when video was the only low-cost option.

By rectifying the captured images to visible ground control surveyed in a known coordinate sys- 


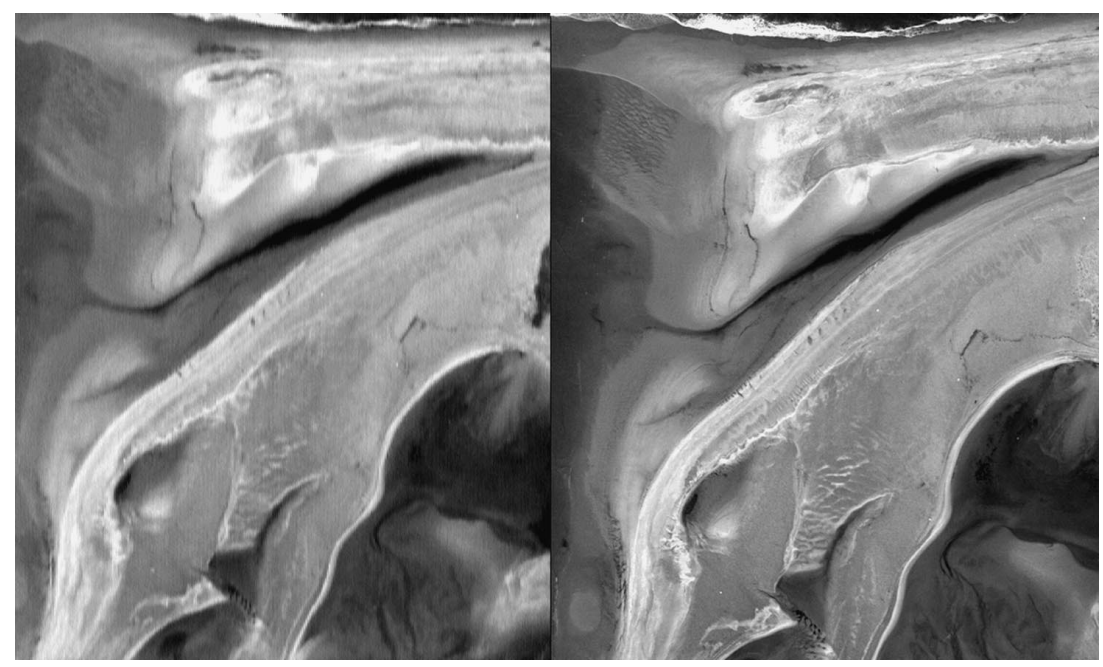

Fig. 4. Video (left) and digital camera (right) images of Far Point compared in November 1997.

tem, it is possible to remove distortion and georeference in a single step. In this study, ERDAS Imagine 8.2 was used to select points on the source image and to rectify the images into the coordinate system of the ground control. The aim of the rectification is to recover attitude, remove lens-based radial distortion and rotate into a coordinate system which then necessitates the resampling of the original pixels of the image to align with the new geometry. The best results should be achieved with, vertical or pseudovertical aircraft capture, a high quality lens with of not too wide an angle, and an area on the ground that is small enough to assume that the coordinates are planar., In such circumstances then, a first order polynomial fit of the points visible in the image to the surveyed ground control should be sufficient and a minimum of only four control points is needed. In practice, these conditions should not be difficult to satisfy.

Table 3 shows the results for the rectification of the digital camera image and the video image shown in Fig. 4, which are typical of the results obtained for the rectification of over a dozen images of both kinds. Using a first order polynomial rectification, the image is transformed to 'best fit' the visible ground control points for which coordinate positions exist. By calculating the root mean square (RMS) of the individual errors (differences between the recti- fied image position and specified coordinate position) the quality of fit can be summarised. Individual errors are variable although not usually greater than double the total RMS. The largest individual errors are associated with isolated ground control points which emphasises the importance of good distribution of control. By examining such rectification results, it is possible to assess the accuracy of the georeferenced imagery. It can be suggested that double the total RMS value is a suitable approximation for a conservative assessment of the positional error.

The greater error in the digital camera imagery, despite its greater resolution, could be because of a combination of the wider angle lens used in the digital camera $(20 \mathrm{~mm})$ and the less vertical deployment (a hand-held mount was used). A wide-angle lens has a greater radial distortion at the edges than the standard video camera lens used; it is possible to compensate for this radial distortion by using camera parameters that were not available in this case. Cam-

Table 3

Rectification results for the two images shown in Fig. 4

\begin{tabular}{lcll}
\hline Image & Size (pixels) & $\begin{array}{l}\text { Control } \\
\text { points }\end{array}$ & $\begin{array}{l}\text { Total RMS } \\
\text { error }(\mathrm{m})\end{array}$ \\
\hline Digital camera & $2036 \times 3060$ & 11 & 2.82 \\
Video camera & $576 \times 768$ & 7 & 1.39 \\
\hline
\end{tabular}



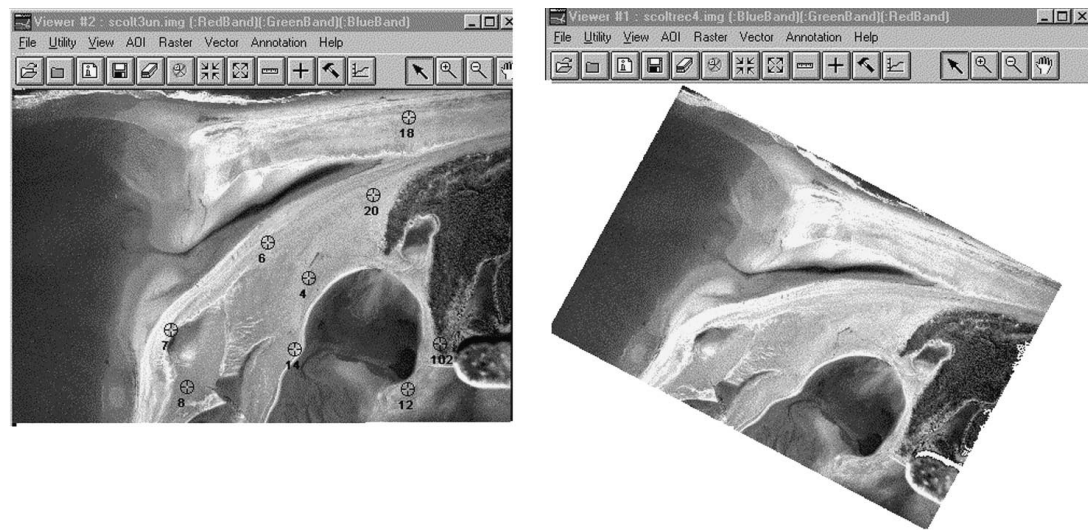

Fig. 5. Image rectification procedure with parameters for 1st degree polynomial transform as derived from Erdas Imagine 8.2 for Windows NT.

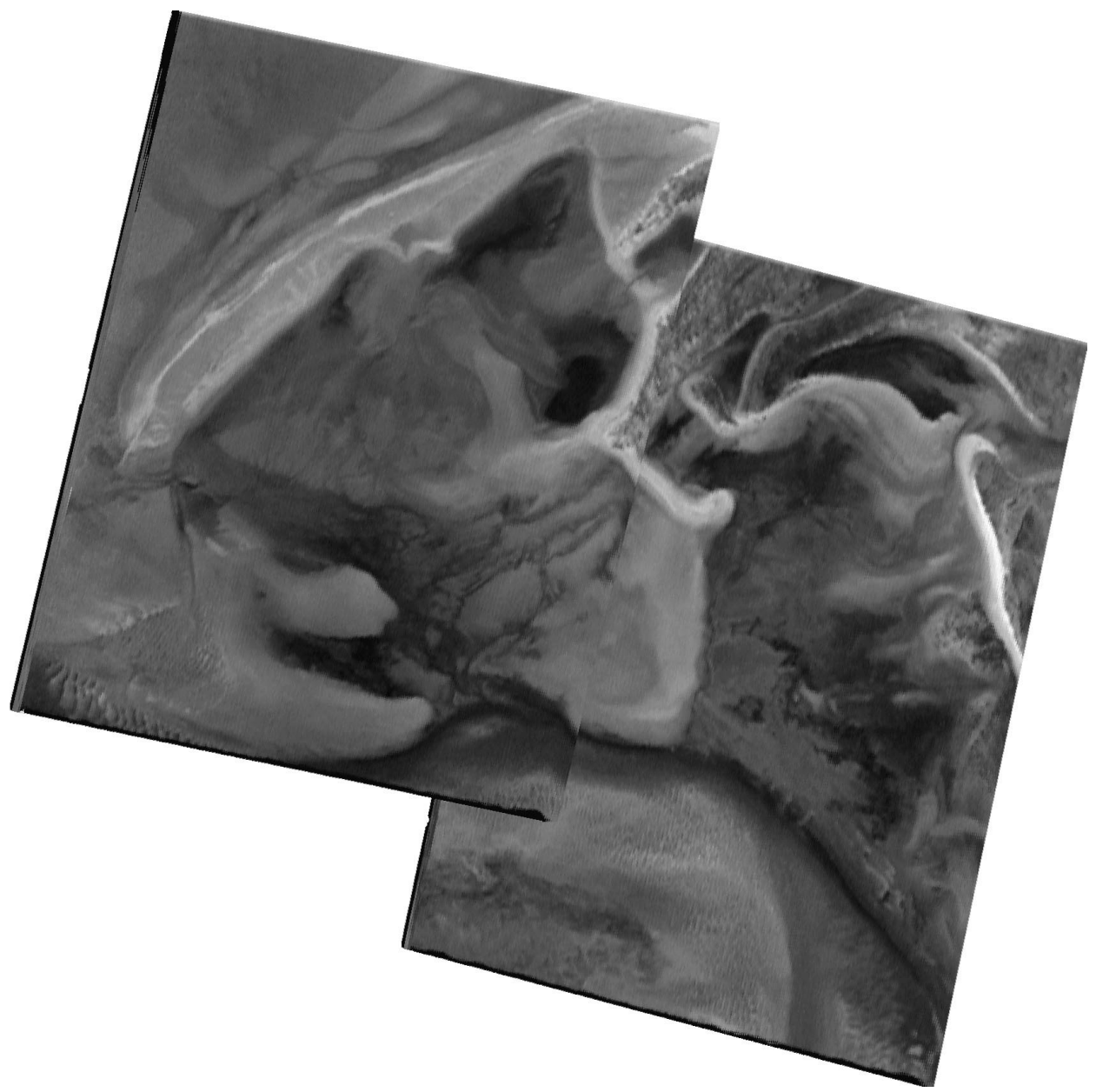

Fig. 6. Video frame mosaic for the Far Point, Scolt Head Island (August 1993). 
era mounts can be used on suitably modified planes to improve the viewing attitude.

These results fall within the bounds of the required accuracy for the geomorphological study specified above, despite the fact that only ground control and a first order transform were used to rectify the image. Experience and observations from the imagery and the way it coincides with the terrain modelling indicate that the errors indicated by the transformation procedures are likely to be a 'worst case' error. In practice, the typical errors are likely to be less than these, especially when confirmatory datasets of greater accuracy are available as a direct comparison, i.e., the surveyed terrain. Given similar conditions, ground control and flying heights, these results should be easily reproducible elsewhere. With further information on camera parameters, a more stable platform and platform attitude control or adjustment, greater accuracy can be expected (Fig. 5).

Once the individual images are rectified to the target coordinate system, they can easily be mosaiced. Ideally, the mosaiced images should share some ground control points, but if the scenes contain unambiguous sharply defined features, it may be possible to pick common points to be used in mosaicing. In this study, shared ground control points were used and second order polynomials were used to mosaic the image. The use of a second order polynomial implies the warping of the ground control points visible in the image to fit the coordinate values given for them. Note that the total RMS of a mosaiced pair of images may be lower than that obtained during the rectification of the individual images. However, this result is achieved at the cost of greater local warping of the image by the second order polynomial. The result of mosaicing two video frames from August 1993 is shown in Fig. 6 in grayscale.

\section{Integration of imagery and terrain models}

Once the imagery has been georeferenced and mosaiced, it can be integrated with terrain data. Ideally, the terrain data used will have a comparable resolution to the imagery, few sources of pre-existing terrain data are likely to be available to meet the specifications of accuracy and resolution achievable by videography and digital photography. In most cases, videography and digital photography should be able to provide a resolution of $<1 \mathrm{~m}$ and a positional accuracy of $<5 \mathrm{~m}$ overall. Accordingly, the terrain data must be surveyed on the ground or produced using photogrammetric stereocorrelation from the imagery. In this study, the terrain data consisted of points chosen at breaks of slope by the authors and surveyed with a total station instrument.

The resolution and accuracy provided by a ground survey is in contrast to the resolution and accuracy of the airborne survey. A ground survey produces data of great accuracy, 0.1 to $10 \mathrm{~cm}$, dependent upon the set up of the theodolite, the atmospheric conditions and the vigilance of the operators. The resolution of the ground survey data is much lower, generally in the range 10 to $20 \mathrm{~m}$ although this is variable over the survey, with the operator providing greater resolution in important or complex areas. In contrast, digital camera imagery can give a resolution across the image of between 15 to $50 \mathrm{~cm}$ while the positional accuracy may be between 1 to $10 \mathrm{~m}$. The fact that the imagery has relatively good resolution but poorer accuracy while the terrain model has extremely good accuracy but poorer resolution, enables the two data sources to complement each other. It is often the case that a study is limited by the poorest quality data. The authors contend that in this case study the different surveys can be used together in a synergistic fashion ("the whole is greater than the sum of the individual parts'). Combining the survey techniques into a co-located framework allows the identification of features with a greater level of confidence and a greater overall accuracy.

\subsection{Visualisation of elevation / image data}

Once the imagery has been georeferenced to the same local co-ordinate system as the ground survey, the image can be used in combination with the survey data as an image map. The image comprises a thematic layer in a GIS system. Using this method, it is possible to overlay survey features such as contour plots and to digitise directly over the image to take measurements. Since a terrain model is available, measurements can be linear, aerial or volumetric. However, in this paper, we will concentrate on visu- 
alisations that can be used with the imagery to aid and enhance interpretation. This is an approach called data visualisation, specifically in three dimensions, and is widespread in many fields of science, where information is available in suitable, computer readable form (Tufte, 1990). Recently, advances in hardware have made it possible for PC-based systems to handle the graphics processing required for $3 \mathrm{D}$ data visualisation, and accordingly GIS software manufacturers are providing the tools to do this on their PC software versions. By draping the imagery and overlay(s) on top of the terrain model, three or more datasets can be compared directly and viewed from different angles and directions. This gives the geomorphologist greater scope for examining spatial relationships in the data.

In the following sections, there are three examples of how the imagery, terrain models and other geomorphic information can be combined to visualise the study area. Software, such as ArcView 3D Analyst and MapInfo/Vertical Mapper, can be used for mapping and visualisation. If required, the resolution can be reduced and the image displayed using a Virtual Reality Modelling Language (VRML) browser so that it is accessible over the World Wide Web.

Fig. 7 shows two digital camera images from November 1997, mosaiced together, georeferenced and draped over the September 1997 terrain. The image is viewed in perspective from the south at a virtual distance of about $750 \mathrm{~m}$ and an inclination of about 35 degrees. The southern end of the main spit has no imagery draped over it and indicates how much harder it is to interpret the terrain without corresponding imagery. Features such as the developing mud flat behind (south of) the main spits and to the west of the dunes are much more clearly evident in this kind of visualisation than in more conventional approaches such as contour plots. If it is desirable to accentuate the topography and to relate contours to the corresponding features on the ground, it is easy to overlay the contours onto the image as another layer (see Fig. 9 below).

The distribution of different sediment types over the spits can be an important indicator of stability and process. Qualitative codes of surface sediment type are recorded during the survey and these can be used to estimate a typical particle size distribution. In modelling efforts that are underway as part of the MAFF research program (MAFF, 1995), sediment simulation modelling (Tetzlaff and Harbaugh, 1989; Martinez and Harbaugh, 1993) is being used to look at controlling factors for spit development. The simulation model used is SEDSIM which requires a particle size distribution to be specified for the sediment in terms of four, user-defined, grain sizes (very fine, fine, medium and coarse). The qualitative assessments used during the survey can be represented as approximate percentages in these four grain sizes, where (in this case) very fine corresponds to mud, fine to sand, medium to gravel, and coarse corresponds to cobbles/pebbles. During the modelling,

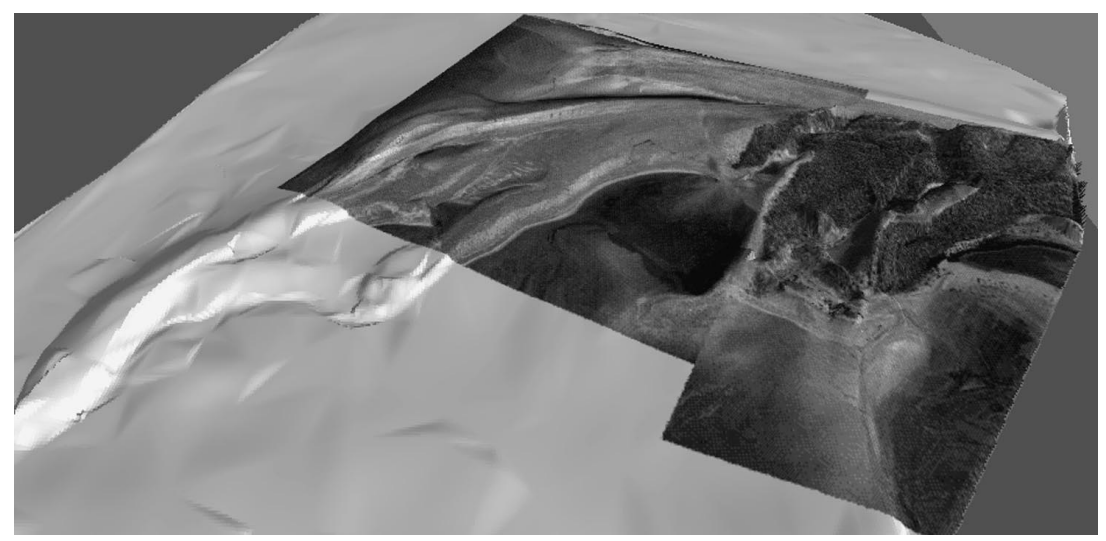

Fig. 7. Perspective view of digital camera image (November 1997) displayed over spits, viewed from the south. 
quantitative values can be assigned to the midpoints of these classes.

Fig. 8, shows Voronoi or Thiessen polygons created around surveyed points, combined with the imagery and draped over the terrain model. The form of the sediment particle size distribution, as estimated using percentages in each size class, is displayed at the centroid of each Voronoi polygon as a histogram. Coarse sediment caps on the spits and fine muds between and behind the spits can act as stabilising influences in the predominantly sandy environment on the Far Point spits. The position and variation of this sediment can be mapped as points and polygons and related to the features and texture on the image. The potential of digital camera imagery for multiband spectral analysis opens up the possibility of using the measurement sites as training areas for a sediment size classification. Initial investigations indicate the superiority of the red band for discerning sedimentary structures and experiments are planned to take this approach a stage further by using a near-infrared band, instead of the blue band which is affected strongly by water.

\subsection{Geomorphological insights gained from image / terrain data integration}

Fig. 9 shows how the imagery and the terrain models can be used to visualise geomorphological change and to give insights into the evolution of the feature under study. Contours of deposition are shown in continuous black, and contours of erosion are shown in dashed gray. The relationship between the most recent series of recurved outer spits and the August 1993 position can be clearly seen in the left hand image (Fig. 9). Four years of net deposition can be seen here and the long term construction of the main spit platform to the north-west (foreground) of the visible spits is picked out. In addition, the degradation and eastward shift of the 1993 outer spit can be seen as it moves into the 1997 configuration and has its sediment supply cut off by the current outer

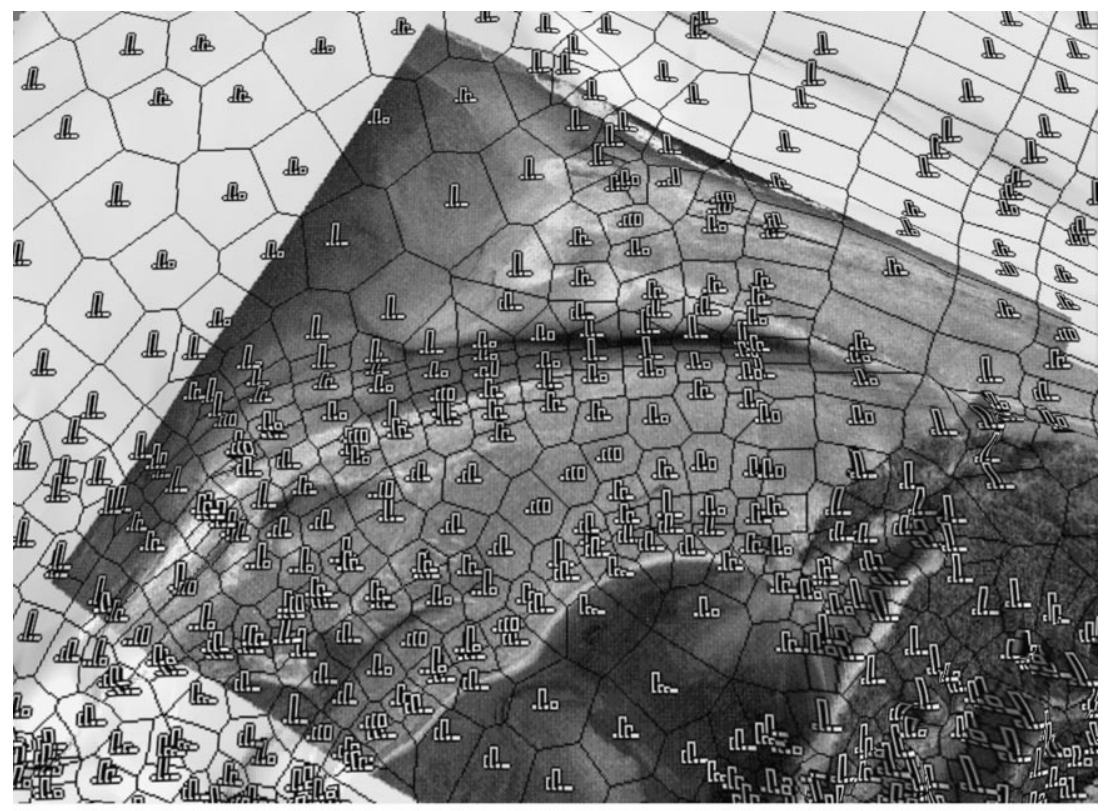

Far Point, Scolt Head Island, Sept/Nov 1997 - Sediment Size Distribution

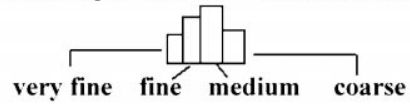

Fig. 8. Qualitative assessment of surface sediment type mapped onto thiessen polygons and displayed as miniature bar charts, draped over a perspective view of a digital camera image, November 1997, viewed from the south. 


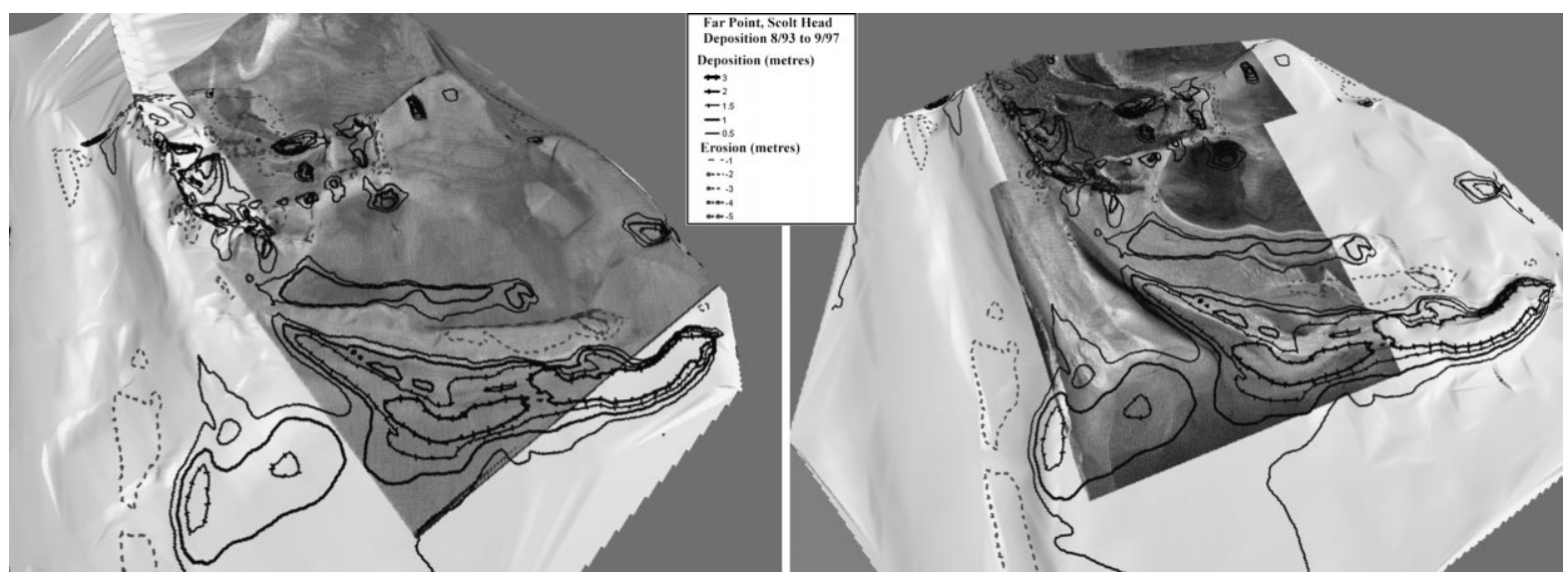

Fig. 9. Contours of change in elevation draped over the August 1993 video imagery (left) and November 1997 digital camera still imagery (right), each viewed from the North West.

spit. A newly forming outer spit is seen to the north east of the main outer spit in 1997. The relative absence of deposition on the main body of this feature indicates that it is occupying a similar position to a corresponding new feature that was present in 1993. This feature, new in 1993, has been extended and recurved to form the body of the 1997 main outer spit.

By extending these two images to a sequence that shows the net accumulative deposition/erosion between the 1993 configuration and the 1997 configuration, the relative, net, sediment movements over this time can be tracked. Such visualisations, can give geomorphological insights into the evolution of the spit features and can be used in combination with more conventional quantitative techniques. They are certainly more informative than the plan form change maps such as that shown in Fig. 2.

\section{Conclusions}

It can be concluded from this study that low cost image collection (where low cost means circa US\$1000 at 1998 prices excluding capital purchase costs) and georeferencing can now be achieved by geomorphologists at acceptable accuracies. A variety of techniques are available and the choice between these techniques depends upon factors such as cost, spatial resolution, temporal requirements and the bounds of required accuracy. The final decision is dependent upon the needs of the geomorphological study, but in the case study discussed in this paper, both videography and digital photography gave acceptable results for the specified purpose. The continuous format, flexibility, cost and availability of standard are the advantages of video, whereas the quality, digital format, and multi-band potential are the advantages of the digital photography. In some ways, the strengths and weaknesses of these two formats are complementary and used together with GPS and ground control for image registration they can be used for different purposes. For example, the two systems can have different field of views with the video giving a broad low scale overview and the digital photography giving a more detailed and accurate large scale view. The continuous nature of the video allows it to be used for capturing dynamic data such as wave orthogonals. The mass storage of an analogue medium allows it to store a continuous record of an extensive site survey that can be linked to a GIS through GPS encoding. Among the benefits of integrating such images with terrain models are the new opportunities for the geomorphologist to record and explore morphodynamic change, as well as in the enhanced ways in which these studies can be visually presented to others.

\section{Acknowledgements}

The authors acknowledge financial support from MAFF, for the capture of some of the imagery and 
terrain data in this paper, as part of a joint project with Babtie Group. Charlie Bristow in Birkbeck College, Department of Geology provided survey equipment and logistical and technical support. Numerous geography and geology students at Birkbeck College and Kingston University helped with the terrain surveys and ground control. English Nature gave permission for the research and have provided logistical facilities for the fieldwork. Flight Logistics provided the aerial platform, Navtech Systems provided video/GPS integration, Airborne Videography recorded the video imagery and Earthlinks coordinated the production of the georeferenced imagery required for this paper.

\section{References}

Bristow, C.S., Horn, D.P., Raper, J.F., 1993. Evolution of a barrier island and recurved spits on a macrotidal coast. Large Scale Coastal Behavior '93, St. Petersburg, FA, USA, November 1993, 21-24. In: List, J. (Ed.), US Geological Survey Open File Report 93-381, 9-12.

Bristow, C.S., Raper, J.F., Livingstone, D.E., in preparation. Morphodynamic changes to recurved spits on the western end of Scolt Head Island, Norfolk.

Carter, R.W.G., 1988. Coastal environments: an introduction to the physical ecological and cultural systems of coastlines, Academic Press, London.

Cooper, R., McCarthy, T., Raper, J.F., 1995. Airborne videography and GPS. Earth Observation 4 (11), 53-55.

Davis, P.G., 1991. Sand and gravel bar migration, Unpublished MSc Thesis, Birkbeck College, University of London.

Eastmann Kodak, 1997. Kodak Digital Science Color Infrared Cameras. Eastmann Kodak, Commercial and Government Services, Technical Specifications, Rochester, NY.

Hayes, M.O., 1979. Barrier island morphology as a function of tidal and wave regime. In: Leatherman, S.P. (Ed.), Barrier Islands Academic Press, New York, 1-28 pp.

King, D.J., 1995. Airborne multi-spectral digital camera and video sensors: a critical review of systems designs and applications. Can. J. Remote Sensing 21 (3), 245-273.
Koh, A., Edwards, E., 1996. Integrating GPS data with fly-on-demand digital imagery for coastal zone management, Proceedings of Association of Geographic Information '96, 6.1.16.1.5.

Lohe, U., 1997. Digital elevation models by laser scanning: principles and applications. Proceedings of the Third International Conference on Airborne Remote Sensing, Copenhagen, Denmark, 7-10 July 1997, I-174-I-180.

Martinez, P.A., Harbaugh, J.W., 1993. Simulating Nearshore Environments, Computer Methods in the Geosciences. In: Simulating Nearshore Environments, Computer Methods in the Geosciences 12 Pergamon, Oxford.

May, J.P., Tanner, W.F., 1973. The littoral power gradient and shoreline changes. In: Coates, D.R. (Ed.), Coastal Geomorphology. Binghampton State University, NewYork.

Meistrell, F.J., 1972. The spit-platform concept: laboratory observation of spit development. In: Schwartz, M.L. (Ed.), Spits and Bars. Dowden, Hutchinson and Ross, Stroudberg, Pennyslvania, pp. 224-284.

Ministry of Agriculture, Fisheries and Food (MAFF), 1992. Flood and coastal defence research and development: report of the Advisory Committee. London, MAFF publications reference PB0864.

Ministry of Agriculture, Fisheries and Food (MAFF), 1995. Flood and coastal defence research development implementation strategy 1994-1998. London, MAFF publications reference PB2249.

Pearson, I., Funnell, B.W., McCave, I.N., 1990. Sedimentary environments of the sandy barrier/tidal marsh coastline of North Norfolk. Bull. Geol. Soc. Norfolk 39, 3-44.

Raper, J.F., 1998. Spatial representation: the scientist's perspective. In: Maguire, Goodchild, Rhind, Longley (Eds.), GIS: Principles and Applications. 2nd edn., pp. 78-95.

Raper, J.F., Livingstone, D., 1995. Development of a geomorphological data model using object-oriented design. Int. J. Geographical Inform. Syst. 9 (4), 359-383.

Steers, J.A., 1960. Scolt Head Island. Heffers, Cambridge.

Tetzlaff, D.M., Harbaugh, J.W., 1989. Simulating Clastic Sedimentation, Van Nostrand-Reinhold, New York, 202 pp.

Tufte, E.R., 1990. Envisioning information, Graphics Press, Cheshire, CT, USA.

Um, J.-S., 1997. Evaluating operational potential of video strip mapping in monitoring reinstatement of a pipeline route. $\mathrm{PhD}$, Univ. of Aberdeen, UK.

Westley, P., Rhind, D., 1993. Mapping for disasters: the OS is ready, but... GIS Europe 2 (2), 37-39. 